\title{
Feelings of dual-insecurity among European workers: $A$ multi-level analysis
}

European Journal of Industrial Relations 20I5, Vol. 2I (I) 23-37

(C) The Author(s) 2014

Reprints and permissions: sagepub.co.uk/journalsPermissions.nav DOI: 10.1 | 177/0959680I|4523।99 ejd.sagepub.com

@SAGE

\section{Wim van Oorschot}

KU Leuven, Belgium

\section{Heejung Chung}

University of Kent, UK

\begin{abstract}
This article analyses European Social Survey data for 22 countries. We assess the relationship between feelings of employment and income insecurity (dual-insecurity) among workers and national flexicurity policies in the areas of lifelong learning, active labour market policy, modern social security systems and flexible and reliable contractual arrangements. We find that dualinsecurity feelings are lower in countries that score better on most flexicurity polices, but these effects are in all cases outweighed by levels of GDP per capita. Thus feelings of insecurity are reduced more by the affluence of a country than by its social policies. However, affluence is strongly correlated with the policy efforts designed to reduce insecurity, especially active labour market policies and lifelong learning, two policy areas that are threatened with cuts as a result of austerity.
\end{abstract}

\section{Keywords}

Flexibility, flexicurity, income and employment insecurity, labour markets, social policy

\section{Introduction}

The European Commission (2007: 10) defined its flexicurity agenda as an integrated strategy to enhance, at the same time, flexibility and security in the labour market. The aim, as defined at the Lisbon European Council (2000), was to reconcile global economic competitiveness and sustainable economic growth with 'more and better jobs and

\section{Corresponding author:}

Heejung Chung, School of Social Policy, Sociology and Social Research, University of Kent, Canterbury CT2 7NF, UK.

Email: h.chung@kent.ac.uk 
greater social inclusion and cohesion'. This quest for a balance between flexibility and security focuses on the flexibility of labour markets, work organization and labour relations needed to support productivity, competitiveness and growth; and security, including employment and income security, especially for weaker groups in the working population, necessary to ensure inclusion and cohesion within society (Wilthagen, 1998). Despite critiques of the flexicurity concept and its implementation (Auer, 2010; Burroni and Keune, 2011; Mailand, 2010; Viebrock and Clasen, 2009), flexicurity is included in the core of the Europe 2020 strategy of the European Commission (2010), and the importance attributed to flexicurity-inspired reforms has increased with the economic crisis (Heyes, 2013; Mandel and Celikel-Esser, 2012).

In order to benchmark and monitor progress towards flexicurity, the Commission has stimulated the development of statistical instruments to measure the achievements of Member States. The most recent and comprehensive (Manca et al., 2010) comprises four standardized composite indicators that correspond to the four dimensions of flexicurity identified by the Commission (2007: 12). This quantifies characteristics of policies and practices in the areas of lifelong learning, active labour market policies, 'modern social security systems' and 'flexible and reliable contractual arrangements'.

This instrument gives a comparative picture of a country's flexicurity policies and spending, and of some company-level practices, but it does not tell whether and to what degree these actually produce flexicurity as an outcome experienced by individual workers. The underlying assumption is that in countries that score higher on the indicators, the flexicurity situation is generally better, including the security an average individual worker feels about their future employment and income. Our study directly addresses the effectiveness of flexicurity policies: whether higher index scores of flexicurity have consequences for how individual workers experience security. Do higher investments in flexicurity policies and practices indeed result in stronger feelings of security? And what elements of the various policies and practices are most effective in this respect?

We focus on the security outcome of flexicurity policies and practices, and not on the flexibility outcome. This is for practical reasons: we have data about workers' perceived security (regarding future employment and income), but not about how they experience flexibility (for example, regarding dismissal protection, working hours and work-life balance). However, if flexicurity policies make workers less insecure, this may stimulate them to be more mobile and flexible on the labour market. If so, achieving the security goal would also support the flexibility goal. Our research question thus concerns the relationship between national flexicurity indicators and perceived insecurity among workers. For a wider insight into the issue we also consider what proportion of workers in Europe feel insecure, and what country characteristics besides flexicurity scores play a role in their insecurity perceptions.

Some initial comments on perceived insecurity are necessary. In flexicurity debates, the security aspect usually relates to people's employment and income (Klammer et al., 2008). Perceived employment insecurity and income insecurity only partly overlap: in the ESS dataset the correlation between feelings of employment insecurity and feelings of income insecurity is .42 at the individual level. But in our view, the most interesting cases are those where they do overlap: when workers experience employment and income insecurity at the same time, a combination which is strongly indicative of 
belonging to the 'precariat' (Standing, 2011). From a citizenship and social cohesion perspective, it is in these 'dual-insecurity' cases (as we refer to them here) that the beneficial effects of flexicurity policies are needed most, and may be most effective. The dependent variable in this study, therefore, distinguishes between workers who feel dual insecurity and others.

\section{Country-level determinants of feelings of insecurity}

\section{Flexicurity indices}

Manca et al. (2010) operationalize the Commission's four dimensions of flexicurity policies: lifelong learning (LLL), active labour market policies (ALMP), modern social security systems (MSS), and flexible and reliable contractual arrangements (FCA). A country's score on each dimension is a composite of a number of relevant indicators. ${ }^{1}$ Here we mention the main characteristics of each composite index, and then we formulate our hypotheses.

The LLL index concerns strategies to ensure the continuous employability of workers, and is calculated from national data on the percentage of firms providing continuing vocational training, financial investment in such training and the proportion of (male and female) employees participating in education and training in general and vocational training in particular. The ALMP index covers policies aimed at reducing spells of unemployment and easing transitions to new jobs: training, job-sharing, job creation and employment incentives. The index is based on government spending on such activities as a percentage of GDP, per participant and per person willing to work. The MSS index includes unemployment benefits that provide adequate income support, encourage employment and facilitate labour market mobility, as well as services that facilitate the combination of work and child care. It is calculated on the basis of 20 indicators. The FCA index covers labour law, collective agreements and work organization. It is composed of 19 indicators including regulations on dismissals and flexible contracts (external flexibility), working-time flexibility (internal flexibility), and flexible arrangements to help combine work and family responsibilities.

The main aim of flexicurity policies is to provide a move from job security to employment and income security (European Commission, 2007). Employment protection legislation (EPL) and unemployment benefits (UB) may be functional equivalents in this regard: one provides job security and the other income security (Standing, 1999). Schmid (1995: 57) suggests that if one type of labour market policy is underdeveloped the other may replace or offset it. The Danish flexicurity model moves from providing job security via EPL to providing income and employment security through enhancing the employability of the workers through ALMP and a high level of UB (Madsen, 2003).

Our hypothesis is that the composite indices LLL, ALMP and MSS are negatively related to our dependent variable, dual-insecurity, because all three reflect policies and practices aimed at increasing income and employment security; hence people living in countries with higher scores on LLL, ALMP and MSS should feel less insecure. We are interested in whether the effects of these three indices differ, because they all have a distinctive character: LLL mainly reflects the policies and practices of firms, ALMP 
reflects an activating, employment-oriented approach in national social protection policies and MSS reflects a 'passive', benefits-oriented approach.

The impact of flexicurity indicators on insecurity perceptions has not been tested empirically thus far, but some research findings offer clues and caveats. Regarding the effect of UB systems (which are part of the MSS index), Clark and Postel-Vinay (2009) found that workers in private companies and with temporary contracts feel more secure in countries where these schemes are generous. The same was found in studies by the OECD (2004) and by Pacelli et al. (2008), where generous unemployment benefits were correlated positively with workers' perceptions of employment security. On the other hand, Erlinghagen (2008) and Chung and van Oorschot (2011), using multi-level models for European countries, found that social security spending shows no significant effects when macroeconomic and labour market indicators are taken into account. OECD (2004) shows that ALMP is positively correlated with feelings of security. Anderson and Pontusson (2007) show that spending on ALMP has no statistically significant impact on perceived job insecurity when other factors are controlled for, but does decrease labour market insecurity, that is the feeling that one would be unable to find an appropriate job once unemployed. This points to the necessity of controlling for other country characteristics when testing the effects of the flexicurity indices.

As regards the FCA index, empirical studies of the effects of EPL on job insecurity are relevant. A number of findings show that stricter EPL may have a negative impact on feelings of employment security by leading to longer duration of unemployment (Nickell, 1997), greater use of temporary contracts (Dolado and Jimeno, 2002; OECD, 2004; Polavieja, 2006) and stronger insider-outsider division (Boeri et al., 2001: 21). Clark and Postel-Vinay (2009) show that especially workers in private companies or with temporary contracts feel less secure in countries with higher EPL. However, other studies show that employment protection levels do not have significant effects when other macroindicators are taken into account (Chung and van Oorschot, 2011; Erlinghagen, 2008). Since EPL constitutes only a portion of the FCA index, we may expect a different outcome when other components of the FCA index are taken into account.

\section{Other socio-economic contexts}

In addition to these institutional factors, the socio-economic characteristics of a country also play a role in influencing dual-insecurity, especially labour market conditions. Böckerman (2004) found perceived job insecurity to be positively correlated with unemployment rates. Clark and Postel-Vinay (2009) show that five-year average local unemployment rate increases the perceived job insecurity of temporary workers, but decreases that of permanent workers. Changes in the unemployment rate from the previous year are also important, especially when assessing the prospect of keeping one's current job or finding another (Anderson and Pontusson, 2007: 222). However, Green et al. (2000) found in Britain that annual changes in unemployment seem to have no effect on perceptions of job insecurity, but both the unemployment rate and annual changes in unemployment significantly increased individuals' perceptions of difficulties in finding a new job. Erlinghagen (2008) used long-term unemployment rates in his multi-level analyses and found a significant negative impact on perceived job insecurity. Therefore we predict 
that higher unemployment rates and recent increases in these rates will have a negative effect on feelings of dual-insecurity.

General economic conditions may also influence insecurity feelings by affecting both the actual possibility of losing and finding jobs and also people's concerns about their future jobs and income. Most cross-national studies of employment insecurity use average GDP growth rates to measure economic conditions; but the findings are contradictory and country-specific (Chung and van Oorschot, 2011; Erlinghagen, 2008). We include economic indicators, which may be particularly relevant since we use data from late 2008 and early 2009, when the financial crisis began; the recession may have had a major impact on individuals' feelings of dual-insecurity. Similarly, GDP levels can also affect socio-economic insecurity: richer countries may have more resources to alleviate income insecurity. Mau et al. (2012) show that individuals in countries with higher GDP per capita are less prone to perceive socio-economic insecurity.

Regarding the effects of the economic context on income insecurity, we cannot refer to previous findings because, surprisingly, the literature on perceptions of income insecurity is extremely scarce, largely limited to studies of savings decisions by private households (Das and Donkers, 1999) and of concerns about their income levels in retirement (Litwin and Sapir, 2009). Nevertheless, one would expect perceptions of income insecurity and thus of dual-insecurity to be higher in countries with higher poverty rates, because workers generally may be more aware of the income risks of losing their jobs. On the other hand, the poverty rate of a country may reflect the quality of its social security system, which in that case is the crucial factor. We control for this factor partly by including it in our analysis the MSS index, and partly by including the size of overall welfare spending. We did not control for welfare regime type, because Erlinghagen (2008) found no relationship between regimes and feelings of job insecurity. Another factor we include in our model is the level of inequality; many studies view this as detrimental to subjective well-being and life satisfaction (Alesina, 2004; Wilkinson, 2010), which can lead to social insecurity as well (Mau et al., 2012). We predict that countries with larger inequalities will have more dual-insecurity.

\section{Individual-level factors}

To examine the impact of context variables correctly it is necessary to control for the fact that country differences in perceptions of dual-insecurity may partly reflect differences in workforce composition. Therefore we include as controls several individual-level characteristics that may be expected to influence feelings of insecurity. Previous studies on job and employment insecurity (Anderson and Pontusson, 2007; Burgoon and Dekker, 2010; Erlinghagen, 2008; Muñoz de Bustillo and de Pedraza, 2010) indicate that such variables relate to economic and human capital, family structure, employment and workplace features, education, disability, being a part of a minority group, having a partner in paid employment, children, temporary and part-time contacts, having no on-the-job training, previous unemployment and being a union member. The literature also suggests that insecurity perceptions vary across economic sectors. In addition, we control for sex and age.

In short, the main effect in which we are interested is that of flexicurity scores on perceived dual-insecurity, where we control for the possible influence of other relevant 


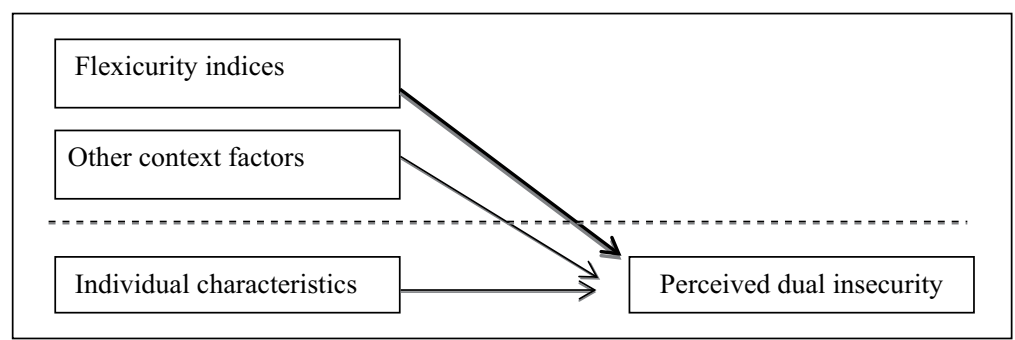

Figure I. Conceptual model for multi-level analysis.

context factors, as well as for a number of individual characteristics. We apply a multilevel approach, which is pictured in our conceptual model in Figure 1.

\section{Data and methods}

\section{Data}

The data used are from the fourth wave of the European Social Survey (ESS 2008/09; for details see www.europeansocialsurvey.org). The dataset covers 31 European countries: the EU 27, excluding Italy and Luxembourg, plus Israel, Norway, Russia, Switzerland, Turkey and Ukraine. We use the ESS because it is one of the few cross-national datasets that survey both perceived employment and income insecurity, and it includes a range of relevant background variables which are not all available in other comparative datasets. We include the 22 countries for which sufficient context data are available: Belgium, Bulgaria, Cyprus, Czech Republic, Denmark, Estonia, Finland, France, Germany, Greece, Hungary, Latvia, the Netherlands, Norway, Poland, Portugal, Romania, Spain, Sweden, Slovakia, Slovenia and the UK. The number of countries in the analysis reduces when analysing the effects of flexicurity indices because lack of data, as will be noted in the text. Since we examine income and employment insecurity in combination, we focus on individuals currently in paid employment, excluding the unemployed, those in education and those over 65 years of age.

\section{Dependent variable}

Employment insecurity is measured using the survey question: 'how likely is it that during the next 12 months you will be unemployed and looking for work for at least four consecutive weeks?' Income insecurity is measured by 'how likely is it that during the next 12 months there will be some periods when you don't have enough money to cover your household necessities?' In both cases the answer categories are not at all likely, not very likely, likely and very likely. Our dependent variable of dual-insecurity is dichotomous: individuals who perceive dual-insecurity (score 1) are those who said that it was likely or very likely that in the coming 12 months they would be unemployed and also likely or very likely that they would not have enough money for household necessities. All others were scored as not perceiving dual-insecurity (score 0 ). 
Table I. Country scores on dual-insecurity and flexicurity indicators.

\begin{tabular}{|c|c|c|c|c|c|c|c|c|c|c|c|}
\hline & D-I ${ }^{a}$ & LLL & ALMP & MSS & FCA & & D- ${ }^{a}$ & LLL & ALMP & MSS & FCA \\
\hline $\mathrm{NO}$ & I & $x$ & 322 & $x$ & $x$ & $\mathrm{SI}$ & 15 & $x$ & 63 & 355 & 563 \\
\hline DK & 2 & 801 & $x$ & 450 & 571 & PL & 16 & 175 & 134 & 300 & 544 \\
\hline $\mathrm{NL}$ & 2 & 621 & 366 & 492 & 571 & $\mathrm{HU}$ & 19 & 282 & 75 & 349 & 420 \\
\hline $\mathrm{FI}$ & 3 & $x$ & 295 & 430 & 590 & PT & 21 & 228 & 127 & 523 & 568 \\
\hline SE & 3 & 808 & 320 & 445 & 455 & $C Z$ & 23 & 551 & 59 & 325 & 419 \\
\hline $\mathrm{DE}$ & 6 & 405 & 262 & 507 & 426 & $\mathrm{EE}$ & 24 & 296 & 29 & 385 & 430 \\
\hline $\mathrm{BE}$ & 7 & 539 & 357 & 554 & 473 & ES & 29 & 356 & 191 & 533 & 452 \\
\hline UK & 7 & 472 & 140 & 351 & 533 & GR & 30 & 37 & $x$ & 451 & 517 \\
\hline$C Y$ & 12 & 317 & $x$ & 434 & $x$ & RO & 33 & 113 & 35 & $x$ & $x$ \\
\hline $\mathrm{FR}$ & 12 & 692 & 246 & 513 & 553 & $B G$ & 41 & 69 & 58 & $x$ & 470 \\
\hline SK & 12 & 382 & 63 & 363 & 448 & LV & 55 & 74 & 39 & 331 & $x$ \\
\hline
\end{tabular}

adual-insecurity, national aggregate percentage.

$\mathrm{x}=$ data not available.

\section{Independent variables}

Our measures of the four composite flexicurity indices are taken from Manca et al. (2010). We took the most recent scores available: LLL for 2005, and ALMP, MSS, and FCA for 2007 (see Table 1). All data on labour market, public expenditure and economic conditions are from EUROSTAT. We include unemployment rate for 2008, and change in unemployment rate for 2008-09, GDP per capita 2008, GDP growth 2008-09, poverty rate 2008, poverty rate change 2008-09, total social expenditure for 2007 (because data were not available for 2008 at the time of the analysis), as well as Gini-coefficient for 2008.

The measures of our individual-level control variables are: age $(15-29,30-39,40-49$, $50-64)$; sex $(0=$ male, $1=$ female $)$; household receiving benefits $(0=$ no, $1=$ yes $)$, educational level two dummy variables were used to indicate basic and tertiary education level while secondary education level was used as a reference group; daily life hampered by disability $(0=$ no, $1=$ yes $)$; ethnic minority $(0=$ no, $1=$ yes $)$; partner in paid work $(0$ $=$ no, $1=$ yes $)$; dependent children $(0=$ no, $1=$ yes $)$; permanent contract $(0=$ no, $1=$ yes $)$; part-time worker $(0=$ no, $1=$ yes $)$; currently member of trade union $(0=$ no, $1=$ yes $)$; training received in the past year $(0=$ no, $1=$ yes $)$; unemployment in the past five years $(0=$ no, $1=$ yes $)$; economic sector of job.

\section{Analyses}

We ran random intercept multi-level logistic regression models; contextual effects are taken into account and individuals are considered to be nested in countries (Hox, 2002). Several models are examined. First, we use an empty or null model to examine the amount of variance of insecurity that can be attributed to the individual and the country level. In the second model we include our individual-level control variables, to test for composition effects. In the third series of models we include each flexicurity index and other country-level variables separately, while controlling for all individual-level 
variables. Fourth, we test the impact of flexicurity scores while controlling for other context variables, and we finally test the impact of combinations of the other context variables. We use STATA 12.0 xtmelogit to derive our results.

\section{Results}

\section{Descriptive analyses}

We see a very large variation between countries in the degree to which workers perceive dual-insecurity (Table 1): from only 1 percent of the working population in Norway to 55 percent in Latvia. Further analyses revealed a strong co-variation (correlation of .92) between a country's percentages of employment-insecure and incomeinsecure workers.

\section{Multivariate, multi-level analyses}

We analyse the effects of the composite flexicurity indicators of LLL, ALMP, MSS, and FCA on individual workers' feelings of dual-insecurity, using a series of multi-level models. First, we find an intra-class-correlation (icc) of 31 percent: hence just under a third of the variation in European workers' dual-insecurity stems from the fact that they live in a particular country. We included the individual-level variables in the model to see what part of the country-level variation is due to differences in the composition of their populations; this accounts for about 18 percent of the country-based variation. As for the effects of individual-level control variables, ${ }^{2}$ insecurity is lower amongst those aged between 55 and 64, but higher for women, individuals with a lower educational level, with a disability, who belong to an ethnic minority, who do not have a working partner, who do not have a permanent contract, not in the union, who have not had recent training but have had previous experience of unemployment. These results confirm most of our expectations and are in line with findings of Mau et al. (2012). As for sectoral effects, insecurity feelings are higher in manufacturing, mining, construction, transport and in hotels and restaurants.

Table 2 shows the results of the analyses where country-level variables are added one by one to a model with all individual-level control variables, to see how they explain the cross-national variance in feelings of insecurity. All four composite flexicurity indicators are related to insecurity perceptions in the expected direction: the higher a country's flexicurity score, the less likely that workers feel both employment and income insecure. The ALMP factor is especially influential: together with the control variables it is responsible for 79 percent of the country-based variation. LLL contributes less $(69 \%)$, while MSS and FCA contribute least (31\% and 41\%). From the last two columns of Table 2, we see that the impact of LLL and ALMP mainly reflects their influence on income insecurity, while MSS and FCA mainly explain cross-national variance in employment insecurity.

The effects of other context variables are also as expected (Table 2). Perceptions of insecurity are higher in countries with higher unemployment, and where unemployment increased in the crisis period. Insecurity is also higher in countries with lower 
Table 2. Multivariate, multi-level regressions.

\begin{tabular}{|c|c|c|c|c|c|c|}
\hline \multirow{2}{*}{$\begin{array}{l}\text { Dependent } \\
\text { variable }\end{array}$} & \multicolumn{4}{|c|}{ Dual-insecurity } & \multirow{2}{*}{$\begin{array}{l}\text { Empl. } \\
\text { insecurity } \\
\begin{array}{l}\text { Standardized } \\
\text { coefficient }\end{array}\end{array}$} & \multirow{2}{*}{$\begin{array}{l}\begin{array}{l}\text { Income } \\
\text { insecurity }\end{array} \\
\text { Standardized } \\
\text { coefficient }\end{array}$} \\
\hline & $\begin{array}{l}\text { Standardized } \\
\text { coefficient }\end{array}$ & $\begin{array}{l}\text { \% Explained } \\
\text { country } \\
\text { variance }\end{array}$ & $N$ level Ia & $N$ level $2^{\mathrm{a}}$ & & \\
\hline \multicolumn{7}{|l|}{ Models ${ }^{\mathrm{b}}$} \\
\hline \multicolumn{7}{|l|}{ Composite indices } \\
\hline LLL(2005) & $-0.688^{* \cdots \cdots k}$ & 69 & 15427 & 19 & $-0.395^{\text {*wok }}$ & $-0.63 I^{* * * k}$ \\
\hline ALMP (2007) & $-0.721^{\text {*wak }}$ & 79 & 15738 & 19 & $-0.503^{* * 2 k}$ & $-0.594^{* * *}$ \\
\hline MSS (2007) & $-0.448^{*}$ & 31 & 15683 & 19 & $-0.359^{*}$ & $-0.339^{*}$ \\
\hline FCA (2007) & $-0.403^{*}$ & 41 & 15286 & 18 & $-0.343^{* *}$ & -0.198 \\
\hline \multicolumn{7}{|c|}{ Other context variables } \\
\hline $\begin{array}{l}\text { Unemployment } \\
2008\end{array}$ & $0.456^{*}$ & 32 & 18017 & 22 & 0.270 & 0.338 \\
\hline $\begin{array}{l}\text { Unemployment } \\
\text { change 2008-09 }\end{array}$ & $0.394^{*}$ & 34 & 18017 & 22 & $0.369^{* \mathrm{kak}}$ & 0.280 \\
\hline GDP/capita 2008 & $-0.810^{\text {*wok }}$ & 83 & 18017 & 22 & $-0.529^{* * k k}$ & $-0.64 I^{* * *}$ \\
\hline $\begin{array}{l}\text { GDP/capita change } \\
\text { 2008-09 }\end{array}$ & $-0.258^{*}$ & 31 & 18017 & 22 & $-0.258^{* *}$ & $0.456^{* *}$ \\
\hline Poverty rate 2008 & $0.582^{\text {*wok }}$ & 55 & 18017 & 22 & $0.396^{\text {*eak }}$ & $0.554^{\text {*opk }}$ \\
\hline $\begin{array}{l}\text { Poverty change } \\
2008-09\end{array}$ & 0.152 & 21 & 18017 & 22 & 0.220 & 0.069 \\
\hline $\begin{array}{l}\text { Total social } \\
\text { expenditure } 2007\end{array}$ & $-0.694^{* * a k}$ & 65 & 18017 & 22 & $-0.504^{* ⿰ \alpha+k}$ & $-0.561^{\text {ithos }}$ \\
\hline $\begin{array}{l}\text { Gini coefficient } \\
\text { 2004-08 }\end{array}$ & $0.530^{\text {seper }}$ & 49 & 18017 & 22 & $0.333^{* *}$ & $0.530^{\text {knok }}$ \\
\hline $\begin{array}{l}\text { Gini coefficient } \\
2008\end{array}$ & $0.477^{k+k}$ & 48 & 18017 & 22 & $0.313^{\text {** }}$ & $0.479^{* * 0 k k}$ \\
\hline
\end{tabular}

$*_{p}<0.05 ; * * p<0.01 ; * * * p<0.001$

aWhere $N$ is less than 18017 (level I) and 22 (level 2) this is because composite indices scores are not available for all countries (see Table I).

${ }^{\mathrm{b}}$ Controlled for individual-level variables.

GDP/capita, and where GDP/capita decreased in the crisis period. Understandably, insecurity feelings are higher in countries with higher poverty levels, in those that spend less on social policies generally, and where there is a high level of inequality. Not related to insecurity feelings is the change in the poverty level during the period of crisis. Of all the context factors, the national income stands out as the one with the strongest influence, as revealed by its high coefficient $(-0.810)$ and the highest degree to which this factor alone accounts for the variation in the dependent variable at country level $(83 \%)$. With the exception of the unemployment rate change, all variables seem to explain the cross-national variance in income insecurity better than employment insecurity.

However, these findings involve 'bivariate' relationships, which do not account for the interrelationship between the context variables. Since such relationships do exist, multivariate analyses can show whether and to what degree a relationship in Table 2 is (partly) mediated by other factors. Because of the relatively small number of countries 
included in our model $(N=18 / 22)$, we are limited in the number of context variables that we can include simultaneously in such analyses. Methodologically, the most we can do is to include two context variables simultaneously (Meuleman and Billet, 2009). So to explore the relative importance of the composite flexicurity indices we control the influence of each by combining them with each of the other context variables in Table 2 that show a significant relationship with insecurity perceptions: unemployment rate 2008, change in unemployment rate 2008-09, GDP/capita 2008, GDP/capita change 2008-09, poverty rate 2008, total social expenditure 2007 and the Gini coefficient 2008. The results are shown in Table 3. This shows that the negative effect of LLL index on insecurity remains significant even when combined with other context variables, but that it is completely suppressed when combined with GDP/capita. The same goes for ALMP: The ALMP effect seems to be robust against other context variables, but it disappears when controlling for national income. The effect of the MSS index on insecurity disappears when other context factors are taken into account, except for the unemployment rate, the poverty rate and to some extent the Gini coefficient. Similarly, the FCA index is suppressed by all other context variables except the poverty rate, GDP growth and the Gini coefficient. It seems again that national income is the prime factor affecting feelings of insecurity among workers: it consistently suppresses effects of the index scores. In addition, for each type of flexicurity index, the models that include national income tend to explain most of a country variance in perceptions: 82, 76 and 83 percent respectively for the LLL, MSS and FCA models. It explains rather less in the case of the ALMP models.

However, since national income is related to the other context variables, we need to check how robust its role is when controlled for these. Again, because of our small $N$ at country level, we can only test models with a maximum of two variables. We found that that GDP/capita suppresses the initial effects of unemployment rate 2008 and social expenditure 2007 as well, while it reduces strongly the initial effects of GDP growth 2008-09, unemployment change 2008-09, the Gini coefficient 2008 and poverty rate $2008 .^{3}$ The models that combine GDP/capita with the last four variables explain most of a country variance in perceptions $(87 \%, 88 \%, 89 \%$ and $91 \%$, respectively). The question now remains which model most realistically reflects the effect of country characteristics on feelings of insecurity. We find that poverty rate and Gini coefficient suppress the impact of other variables, with the exception of GDP/capita and social expenditure. When poverty rate and Gini coefficient are included together in the model, both variables become insignificant because of the high correlation between them, but the standardized coefficient of the former is higher than the latter.

Thus our interpretation is as follows: differences in feelings of employment and income insecurity between the populations of European countries are best explained by differences in national income and in poverty rates. ${ }^{4}$ Our findings broadly corroborate those of other studies, where associations are found between social policy measures and insecurity feelings, but are reduced or suppressed when economic situation are controlled for (Chung and van Oorschot, 2011; Erlinghagen, 2008; Mau et al., 2012).

However, closer examination shows that wealthy countries put more effort into their labour market policies: GDP/capita for 2008 is highly correlated to the LLL and ALMP indices, as well as to the social expenditure index, with correlations of $0.8,0.9$ and 0.8 , 
Table 3. Models combining flexicurity indices with other context variables.

\begin{tabular}{|c|c|c|c|c|c|c|}
\hline \multicolumn{2}{|c|}{ Models ${ }^{\mathrm{a}}$} & \multicolumn{2}{|c|}{ Standardized coefficient } & \multirow{2}{*}{$\begin{array}{l}\text { \% Exp. var. } \\
\text { country level }\end{array}$} & \multirow[t]{2}{*}{$N$ level I } & \multirow[t]{2}{*}{$N$ level 2} \\
\hline Varl & Var2 & Varl & Var2 & & & \\
\hline LLL & $\begin{array}{l}\text { Unemployment rate } \\
2008\end{array}$ & $-0.66 I^{* * * *}$ & 0.107 & 70 & 15427 & 19 \\
\hline LLL & $\begin{array}{l}\text { Unemployment } \\
\text { change 2008-09 }\end{array}$ & $-0.639^{* * * *}$ & $0.239^{* *}$ & 77 & 15427 & 19 \\
\hline LLL & GDP/capita 2008 & -0.274 & $-0.570^{* * * *}$ & 82 & 15427 & 19 \\
\hline LLL & $\begin{array}{l}\text { GDP change } \\
\text { 2008-09 }\end{array}$ & $-0.640^{* * * *}$ & $-0.204^{* *}$ & 79 & 15427 & 19 \\
\hline LLL & Poverty rate 2008 & $-0.587^{* * * *}$ & 0.123 & 70 & 15427 & 19 \\
\hline LLL & $\begin{array}{l}\text { Social expenditure } \\
2007\end{array}$ & $-0.376^{* *}$ & $-0.409^{* *}$ & 80 & 15427 & 19 \\
\hline LLL & Gini coefficient 2008 & $-0.673^{* * *}$ & 0.017 & 69 & 15427 & 19 \\
\hline ALMP & $\begin{array}{l}\text { Unemployment rate } \\
2008\end{array}$ & $-0.695^{* * *}$ & 0.234 & 82 & 15738 & 19 \\
\hline ALMP & $\begin{array}{l}\text { Unemployment } \\
\text { change 2008-09 }\end{array}$ & $-0.655^{\text {**** }}$ & $0.189^{*}$ & 83 & 15738 & 19 \\
\hline ALMP & GDP/capita 2008 & -0.311 & $-0.503^{* *}$ & 85 & 15738 & 19 \\
\hline ALMP & $\begin{array}{l}\text { GDP change } \\
\text { 2008-09 }\end{array}$ & $-0.673^{\text {**** }}$ & -0.090 & 80 & 15738 & 19 \\
\hline ALMP & Poverty rate 2008 & $-0.600^{* * * * *}$ & $0.287^{* * * k}$ & 87 & 15738 & 19 \\
\hline ALMP & $\begin{array}{l}\text { Social expenditure } \\
2007\end{array}$ & $-0.596^{* 0 k \%}$ & -0.162 & 80 & 15738 & 19 \\
\hline ALMP & Gini coefficient 2008 & $-0.63 \mid * * *$ & $0.226^{* *}$ & 85 & 15738 & 19 \\
\hline MSS & $\begin{array}{l}\text { Unemployment rate } \\
2008\end{array}$ & $-0.552^{* *}$ & $0.495^{* *}$ & 51 & 15683 & 19 \\
\hline MSS & $\begin{array}{l}\text { Unemployment } \\
\text { change 2008-09 }\end{array}$ & -0.350 & $0.418^{* *}$ & 56 & 15683 & 19 \\
\hline MSS & GDP/capita 2008 & 0.069 & $-0.842^{* * * k}$ & 76 & 15683 & 19 \\
\hline MSS & $\begin{array}{l}\text { GDP change } \\
\text { 2008-09 }\end{array}$ & -0.343 & -0.173 & 39 & 15683 & 19 \\
\hline MSS & Poverty rate 2008 & $-0.44 I^{* *}$ & $0.47 I^{* * * k}$ & 58 & 15683 & 19 \\
\hline MSS & $\begin{array}{l}\text { Social expenditure } \\
2007\end{array}$ & 0.171 & $-0.753^{* \text { *w* }}$ & 68 & 15683 & 19 \\
\hline MSS & Gini coefficient 2008 & $-0.477^{*}$ & $0.383^{* *}$ & 52 & 15683 & 19 \\
\hline FCA & $\begin{array}{l}\text { Unemployment rate } \\
2008\end{array}$ & -0.338 & 0.210 & 44 & 15286 & 18 \\
\hline FCA & $\begin{array}{l}\text { Unemployment } \\
\text { change 2008-09 }\end{array}$ & -0.367 & 0.139 & 43 & 15286 & 18 \\
\hline FCA & GDP/capita 2008 & -0.105 & $-0.693^{* \cdots * k}$ & 83 & 15286 & 18 \\
\hline FCA & $\begin{array}{l}\text { GDP change } \\
\text { 2008-09 }\end{array}$ & $-0.410 *$ & 0.027 & 41 & 15286 & 18 \\
\hline FCA & Poverty rate 2008 & $-0.404^{* *}$ & $0.410^{* *}$ & 57 & 15286 & 18 \\
\hline FCA & $\begin{array}{l}\text { Social expenditure } \\
2007\end{array}$ & -0.158 & $-0.576^{* * * k}$ & 69 & 15286 & 18 \\
\hline FCA & Gini coefficient 2008 & $-0.443^{* *}$ & $0.332^{*}$ & 56 & 15286 & 18 \\
\hline
\end{tabular}

$*_{p}<0.05 ; * * p<0.01$; *** $p<0.001$.

aControlled for individual level variables. 
respectively. Poverty rate and Gini coefficient are also highly correlated with LLL indices, with a correlation of - 0.8 . In addition, although GDP/capita only shows a correlation with MSS at a 0.5 level, it is highly correlated with passive labour market policy expenditure as a percentage of GDP, at a 0.7 level. Given these interrelationships it could be that GDP/capita is an indicator representing a bundle of social policy efforts, in training, activation and income maintenance. In sum, statistically we find the impact of national income and the poverty rate to be important throughout our models; but we can also see that governments in affluent countries make greater efforts (as a percentage of GDP) to ensure better employability as well as better income maintenance. Thus perhaps there is evidence to say that LLL and ALMP (and somewhat MSS or passive labour market policies) are important influences on insecurity feelings. The importance of LLL and ALMP is also backed up by the fact that the effects of both indices are consistently significant even when other context variables (apart from GDP/capita) are included in the model, as we see in Table 3.

Additional analysis ${ }^{5}$ of the relationship between the flexicurity composite indices for LLL and ALMP and dual-insecurity showed that indeed countries with lower GDP/ capita have lower flexicurity scores for both LLL and ALMP compared to richer countries, and also have higher percentages of individuals feeling dual-insecure. In addition, although both policy indices explain the cross-national variance of the proportion of individuals feeling dual-insecure, this is especially true for those with GDP/capita lower than the average for the 22 countries $\left(R^{2}\right.$ of $28 \%$ vs $8 \%$ for LLL, and $37 \%$ vs $26 \%$ for ALMP). On closer inspection it seems that the relationship between these two flexicurity indices and the proportion of the population feeling dual insecure could be considered quadratic ( $R^{2}$ of $62 \%$ for LLL and $72 \%$ for ALMP), where an increase in LLL and ALMP index scores helps decrease the proportion of people feeling dual-insecure dramatically when comparing countries with low to mid-range index scores. However, this impact disappears in the group of countries with relatively higher LLL and ALMP indices.

\section{Discussion and conclusions}

The European Commission has put strong emphasis on flexicurity as a policy to enhance both flexibility and security in labour markets, and it still frames its Europe 2020 strategy. In addition, the Commission continues to stimulate the construction of flexicurity indices for monitoring and benchmarking policies in European countries. The most recent and comprehensive set of indices distinguishes four dimensions: LLL, ALMP, MSS and FCA. A country's score on each of these dimensions is a composite of a number of indicators. The main question addressed in this study is whether these scores have consequences for individual perceptions of (in)security. In other words, do higher investments in flexicurity policies and practices result in stronger security perceptions? In a series of multi-level models, we regressed the index scores, in combination with a series of other country characteristics, on workers' dual-insecurity perceptions: the extent to which they feel simultaneously insecure about their future employment and future income. We controlled for a number of relevant individual characteristics, in order to reveal and account for composition effects. 
A descriptive analysis shows a large variation between European countries in the degree to which workers feel dual-insecurity. The average in our sample of countries is 12 percent, but levels vary from 1 to 55 percent. Dual-insecurity perceptions are especially a problem in the Southern and Eastern parts of Europe. We find that about 18 percent of the individual-level variation in such perceptions stems from living in a particular country. As expected, people in countries with higher flexicurity scores, especially for LLL and ALMP, are less likely to perceive dual-insecurity. However, these associations turn insignificant when the index scores are combined with GDP/capita, that is, with a country's national income.

We also find that affluent countries are those that spend a relatively high proportion of GDP on their social policies, and accordingly the level of both active and passive labour market policy spending is higher. Thus in these countries, flexicurity indices (especially for ALMP and LLL) are also higher. In this sense, what we are capturing with GDP per capita need not necessarily be only national income, but an overall regime where affluence induces a more general effort to provide workers with better training and employability, and thus where poverty rates are lower (another factor that showed a significant impact). Taking this into consideration, we can then say that wealthier countries, where more effort is taken to train and activate their (unemployed) workforce, are those where people are in general more likely to feel secure about both their future employment and income. This result is especially important when we consider that these are two areas of social policy where most countries are inflicting cuts as a consequence of austerity measures (Heyes, 2013). If flexicurity is a policy approach aimed at providing people with security through flexibility, the wealthier countries in Europe should resist cuts in the policy areas that help in providing individuals with a sense of security. For the less wealthy countries, our results suggest that investing in flexicurity policies may be a direct way of reducing feelings of insecurity among their working populations.

\section{Funding}

This research was part of a wider project on welfare state tensions financed in the framework of the EU FP6 Network of Excellence 'Reconciling Work and Welfare'.

\section{Notes}

1. In comparative welfare state analysis it is common to use composite indices for ranking and comparing countries; the flexicurity indices follow this tradition. Such indices are however problematic. The selection and weighting of the components may be arbitrary, so that index scores may not prove reliable if reconstructed by other researchers (Scruggs and Allan, 2006). It is often difficult to have time-series data for a long period of time and a large number of countries, and social and economic change may render indices outdated. In the case of the flexicurity indices, it can be questioned whether combinations of component sub-parts reflecting policies as well as their outcomes leads to an over-estimation of a component's internal consistency; to check this, one could analyse the effect of each sub-part separately, but the detailed data necessary are not available.

2. Full results are available in the Appendix of Tables and Figures published under 'Publications English Articles' on the website: https://perswww.kuleuven.be/ u0079125/. See Table App 2.

3. For full results see Table App 5, available as above. 
4. To check whether models that combine other country characteristics might perform better, we analysed all possible combinations; but all such combinations explain considerably less of the country variation models that include the wealth variable.

5. See Figure App 2, available as above.

\section{References}

Alesina A, Di Tella R and MacCulloch R (2004) Inequality and happiness: Are Europeans and Americans different? Journal of Public Economics 88(9): 2009-2042.

Anderson CJ and Pontusson J (2007) Workers, worries and welfare states: Social protection and job insecurity in 15 OECD countries. European Journal of Political Research 46(2): 211-235.

Auer P (2010) What's in a name? The rise (and fall?) of flexicurity. Journal of Industrial Relations 52(3): 371-386.

Böckerman P (2004) Perception of job instability in Europe. Social Indicators Research 67(3): 283-314.

Boeri T, Börsch-Supan A, Tabellini G, Moene KO and Lockwood B (2001) Would you like to shrink the welfare state? A survey of European citizens. Economic Policy 16(32): 9-50.

Burgoon B and Dekker F (2010) Flexible employment, economic insecurity and social policy preferences in Europe. Journal of European Social Policy 20(2): 126-141.

Burroni L and Keune M (2011) Flexicurity: A conceptual critique. European Journal of Industrial Relations 17(1): 75-91.

Chung $\mathrm{H}$ and van Oorschot W (2011) Institutions versus market forces: Explaining the employment insecurity of European individuals during (the beginning of) the financial crisis. Journal of European Social Policy 21(4): 287-301.

Clark A and Postel-Vinay F (2009) Job security and job protection. Oxford Economic Papers 61(2): 207-239.

Das M and Donkers B (1999) How certain are Dutch households about future income? An empirical analysis. Review of Income and Wealth 45: 325-338.

Dolado JJ and Jimeno JF (2002) Drawing lessons from the boom of temporary jobs in Spain. Economic Journal 112(480): 270-295.

Erlinghagen M (2008) Self-perceived job insecurity and social context: A multi-level analysis of 17 European countries. European Sociological Review 24(2): 183-197.

European Commission (2007) Towards Common Principles of Flexicurity: More and Better Jobs through Flexibility and Security. Luxembourg: Publications Office.

European Commission (2010) Europe 2020: A European Strategy for Smart, Sustainable and Inclusive Growth. COM(2010)2020. Brussels: European Commission.

European Council (2000) Presidency conclusions. Available at http://www.consilium.europa.eu/ uedocs/cms_data/docs/pressdata/en/ec/00100-r1.en0.htm

Green F, Felstead A and Burchell B (2000) Job insecurity and the difficulty of regaining employment: An empirical study of unemployment expectations. Oxford Bulletin of Economics and Statistics 63: 855-883.

Heyes J (2013) Flexicurity in crisis: European labour market policies in a time of austerity. European Journal of Industrial Relations 19(1): 71-86.

Hox JJ (2002) Multilevel Analysis: Techniques and Applications. Hillsdale, NJ: Lawrence Erlbaum.

Klammer U, Muffels R and Wilthagen T (2008) Flexibility and security over the life course: Key findings and policy messages. Available at http://www.eurofound.europa.eu/pubdocs/2008/61/en/1/EF0861EN.pdf

Litwin H and Sapir E (2009) Perceived income adequacy among older adults in 12 countries. The Gerontologist 49(3): 397-406. 
Madsen PK (2003) 'Flexicurity' through labour market policies and institutions in Denmark. In Auer P and Cazes S (eds) Employment Stability in an Age of Flexibility: Evidence from Industrialized Countries. Geneva: ILO, pp. 59-105

Mailand M (2010) The common European flexicurity principles: How a fragile consensus was reached. European Journal of Industrial Relations 16(3): 241-257.

Manca AR, Governatori M and Mascherine M (2010) Towards a set of composite indicators on flexicurity: A comprehensive approach. EU JRC Scientific and Technical Reports.

Mandel I and Celikel-Esser F (2012) The Second Phase of Flexicurity: An Analysis of Practices and Policies in the Member States. Dublin: European Foundation.

Mau S, Mewes J and Schöneck NM (2012) What determines subjective socio-economic insecurity? Context and class in comparative perspective. Socio-Economic Review 10(4): 655-682.

Meuleman B and Billet J (2009) A Monte Carlo sample site study: How many countries are needed for accurate multilevel SEM? Survey Research Methods 3(1): 45-58.

Muñoz de Bustillo R and de Pedraza P (2010) Determinants of job insecurity in five European countries. European Journal of Industrial Relations 16(1): 5-20.

Nickell S (1997) Unemployment and labor market rigidities: Europe versus North America. Journal of Economic Perspectives 11(3): 55-74.

OECD (2004) Employment Outlook 2004. Paris: OECD.

Pacelli L, Devicienti F, Maida A, Morini M, Poggi A and Vesan P (2008) Employment Security and Employability: A Contribution to the Flexicurity Debate. Dublin: European Foundation.

Polavieja JG (2006) The incidence of temporary employment in advanced economies: Why is Spain different? European Sociological Review 22(1): 61-78.

Schmid G (1995) Institutional incentives to prevent unemployment: Unemployment insurance and active labor market policy in a comparative perspective. Journal of Socio-Economics 24(1): 51-103.

Scruggs L and Allan J (2006) Welfare state de-commodification in eighteen OECD countries. Journal of European Social Policy 16(1): 55-72.

Standing G (1999) Global Labour Flexibility: Seeking Distributive Justice. Basingstoke: Macmillan.

Standing G (2011) The Precariat: The New Dangerous Class. London: Bloomsbury Academic.

Viebrock E and Clasen J (2009) Flexicurity and welfare reform: a review. Socio-Economic Review 7(2): 305-331.

Wilkinson R and Pickett K (2010) The Spirit Level: Why Equality is Better for Everyone. London: Penguin.

Wilthagen T (1998) Flexicurity? A New Paradigm for Labour Market Reform. WZB Discussion Paper FS I 98-202, Berlin.

Wulfgramm M. (2011) Can activating labour market policy offset the detrimental life satisfaction effect of unemployment? Socio-Economic Review 9(3): 477-501.

\section{Author biographies}

Wim van Oorschot is Professor of Social Policy at the Centre for Sociological Research, KU Leuven, Belgium.

Heejung Chung is Lecturer in Sociology and Social Policy at the University of Kent, UK. 